\title{
From rice fields to brackish water farms: changing livelihoods in agrarian coastal Bengal, India
}

\author{
Tarun Goswami $^{1}$ (D) Somnath Ghosal ${ }^{1}$
}

Received: 31 August 2021 / Accepted: 18 January 2022 / Published online: 7 February 2022

(c) The Japan Section of the Regional Science Association International 2022, corrected publication 2022

\begin{abstract}
The present study attempted to understand the dimensions of changing agrarian livelihoods because of haphazard adaptation of capitalistic shrimp aquaculture. Specifically, using multi-temporal Google-based geodatabase, we quantified the artificial conversion of agrarian landscape in an inland freshwater region of coastal Bengal. Further, we examined the long-term viability of transformed livelihoods by adopting a modified version of the Sustainable Livelihood Approach (SLA). The assessment of changing livelihoods was based on empirical information acquired through field surveys, focus group discussion (FGD) and key informant interviews (KII). Results from the geostatistical analysis depicted that the shrimp culture in the research area was very recent. In 2010, only 0.03 percent of the total area was occupied by shrimp ponds. However, within a decade and an expansion rate of 18 percent/annum, the conversion spread to $1 / 3$ of the total study area. The findings also clarified that the adaptation of shrimp cultivation increased the overall profit by $6400 \mathrm{USD} / \mathrm{ha} / \mathrm{year}$ over agricultural output, and resulted in a quick rise in the standard of living for the shrimp farmers. However, in the long run, due to decreasing productivity and salinization of the surrounding land, the conversion resulted in massive depeasantization, augmentation of wasteland, and biased wealth accumulation led to a wide rich-poor gap. Therefore, the entire ecosystem will suffer in the near future, if the local government does not strictly impose Standard Operating Procedures (SOPs).
\end{abstract}

Keywords Inland aquaculture $\cdot$ Depeasantization $\cdot$ Sustainable livelihood approach (SLA) $\cdot$ Livelihood vulnerability $\cdot$ RS and GIS

Tarun Goswami

tarun.goswami1998@gmail.com

Somnath Ghosal

somnath@iitkgp.ac.in

1 Centre for Rural Development and Innovative Sustainable Technology, Indian Institute of Technology (IIT) Kharagpur, Kharagpur 721302, India 


\section{Introduction}

The primary concern of the developing world in this current era of globalization is that it must comply with several institutional laws addressing environmental preservation and conservation. At the same time, it has to ensure that the growing population has access to adequate and sustainable food and shelter (Chougrani and El Amrani 2021). On the other hand, based on our possibilistic approach, we, the human beings, have always meant to modify the natural environment at the individual and communal levels to meet our growing societal and biological demands (Lawrence et al. 2013; Dutta et al. 2016). Therefore, collectively environmental exploitation is increasing day by day through the transformation and intensification of human activities (Belton et al. 2020; Schmidt et al. 2020).

India is a monumental example from the developing world, where the economy is changing with the rapid transformation of each sector to meet the needs of its huge population. In coastal regions, land conversion into aquaculture is one of such dominant phenomena. Having a favorable subtropical climate for brackishwater aquaculture and a suitable coastal area of 11.91 lakh hectares spread over ten states (Johny and Madhusoodana 2007; NABARD 2018), the shrimp production and associate land-use conversion in India started expanding since the 1980s (Prasad et al. 2019). As per the Food and Agriculture Organisation (FAO) production statistics, shrimp production in India increased from 119,407 tons in 2010 to 739,161 tons in 2017 (FAO Fish-Stat 2020), which shows clear evidence of the mentioned reckless expansion. Several studies predicted that this expansion would continue in the future (Duarte et al. 2007; Merino et al. 2012), in spite of worries regarding the long-run viability of the industry (Naylor et al. 2000).

Among different production hubs of saltwater shrimp in India, West Bengal is considered the second-highest producer of shrimp after Andhra Pradesh (NABARD 2018). It has the most significant potential impounded brackish water area covering around 405,000 hectares (Ministry of Agriculture, GOI) of the coastal region spread over three districts, i.e., East Medinipur, North Twenty-Four Parganas, and South Twenty-Four Parganas (NABARD 2018; The Fish Site 2021).

Nowadays, the expansion is not only restricted to the coastal tide-affected areas (Le et al. 2018). Instead, in West Bengal, it is expanding more and more towards the interior freshwater agricultural blocks. Where the productive agrarian lands are getting converted (Maiti 2019; Rajakumari et al. 2020), and the process of massive depeasantization comes into the picture (Paprocki and Cons 2014). The depeasantization $^{1}$ or occupational transformation has two-way recursive primitive accumulation; firstly, it is the negative repercussions and at the same time a precondition for expansion of capitalist shrimp production (Adnan 2013). In the present study area (Bhagwanpur II block, East Medinipur), such landscape conversion-led

\footnotetext{
1 Depeasantization is the loss of peasant practices, and it is considered a subset of degradation of the agricultural landscape in which peasants lose economic capability, social cohesion, and demographic size. Several authors have already used this word to explain the erosion of an agricultural way of life (George 2012; Anzar 2020).
} 
depeasantization is very common. Inhabitants of this region convert the natural ecosystem artificially to adopt capitalistic shrimp farming. They dig their agricultural land, fill it with fresh cannel water sometimes by pumping groundwater, then mix salt and chemical fertilizers in freshwater to make it suitable for shrimp production (Field Survey). Apart from these intentional conversions, other factors also work as a mediating factor of depeasantization. Such as the growing aquaculture systems continuously making the surrounding agrarian landscape unproductive through saline water intrusion (Chowdhury et al. 2010; Rajarshi and Santra 2011; Jayanthi et al. 2020) and creating the precondition for further expansion by making smallscale farming difficult and expensive (Jayanthi et al. 2020).

To consider these vulnerabilities of such haphazard growth of shrimp aquafarm, it is essential to quantify the process of expansion. Since the majority of these brackish water fishing ponds are illegal/unauthorized, it is hard to obtain information about the altered land uses from land revenue and fisheries offices (Dutta et al. 2016). Under this circumstance, remote sensing coupled with GIS can be a very useful tool. The obtained spatial databases from remote sensing are not only well fitted for visualizing the change but also provide various statistical information for calculating the trend of transformation (Williams et al. 2015; Das et al. 2016).

There are several social researchers also who mainly pointed out its positive impacts when it has been practiced in the coastal environment. Such as elevation of household income (Hamid and Mohammad 1998; Jahan et al. 2010), greater food security, expanded work possibilities (Gammage et al. 2006), and the increasing number of wage earners (Sharmin and Ali 2005; USAID 2006; Belton and Thilsted 2014). Some of them are primarily concerned with the greater earning potential for women in the household (Gammage et al. 2006; Islam 2009). Other studies have revealed a wide range of adverse environmental, economic, and societal consequences (Ahmed et al. 2010; Belton and Thilsted 2014; Jahan et al. 2014; Toufique and Belton 2014). However, only a few sociological studies have been conducted in the inland freshwater environment, where catastrophic agrarian transformations for capitalist accumulation are happening by destroying productive agricultural land. Therefore, it is indispensable to understand the capability of this kind of rapid transformation in bringing sustainable positive difference in the livelihood system for a large number of reliant people.

The SLA is a widely used framework in this regard (DFID 1999; El Bilali et al. 2017; Barnes et al. 2017; Mistri 2019). Studies have used this framework to analyze different influences, viz., constraints, and opportunities on livelihoods and ensure the essential influencers are not neglected (Ashley and Carney 1999). Ahmed et al. (2010), in his study of "Prawn postlarvae fishing in coastal Bangladesh: associated challenges for sustainable livelihoods", used the SLA to understand the role of shifting occupation to prawn fishing in poverty reduction of an agriculturally underdeveloped region. Wang et al. (2021) considered the SLA to reveal the impact of livelihood capital endowment (LCE) on households' income growth and poverty alleviation under different rural land consolidation (RLC) situations. SLA is also helpful in analyzing the influential parameters behind the diversified livelihood choices of rural households (Huang et al. 2021). 
Thus, to provide a holistic view, the present study is designed in three phases. In the first phase, the study attempted to quantify such land conversion in an inland agricultural region of the East Medinipur district of coastal West Bengal through GIS and remote sensing data. After that, it tries to detect the changing economics, livelihood opportunities, and sustainability compared to the agricultural society using the SLA framework. Finally, it highlights the coping strategies the people have adopted to manage the livelihood constraints and significant risks they face in the long term.

The findings of this study are the micro-level empirical elaboration of the rapid occupational shift of the agricultural society/depeasantization and how it led to longterm threefold vulnerabilities, i.e., environmental, socioeconomic, and livelihood for an inland agriculturally prosperous region of a coastal district of West Bengal, India. It will be helpful for economists, geographers, and policymakers to make some suitable sustainable plans in combating the vulnerability issues for similar situations.

\section{Materials and methods}

\subsection{Introducing study area}

The current research was carried out in Bhagwanpur II C.D. block of the East Medinipur district of West Bengal. In this district, different coastal C.D. blocks such as Deshapran, Ramnagar I, II, Contai I, II, III, are already facing various positive as well as negative livelihood issues related to shrimp farming (Dutta et al. 2016; Maiti 2019; Maity et al. 2019; Rajakumari et al. 2020). However, these coastal blocks are tide-affected and have minimal production in agriculture. In contrast, Bhagwanpur II is one of such productive agricultural blocks where the conversion process has acted livelihood sustainability and self-sufficiency issues. For a detailed study, seven villages are chosen from the block, according to our criteria of widened agricultural land transformation into the salty water body (Fig. 1).

The villages are Nayabasan, Katapukhuria, Ramchak, Raghunathchak, Natagachia, Jiagodi, and Uttar Khasmulda.

The topography of the study area is mainly characterized by gently sloping flat terrain composed of deposited older and patches of younger alluvium. Geologically it is underlined by unconsolidated alluvial sediments of Quaternary age and Mio-Pliocene tertiary sediments layers (Chakraborty 2017; Halder et al. 2021). The occurrence of groundwater aquifer here is generally seen in the leaky confined aquifer system at 20-120 m BGL, and the piezometric level varies from 5 to $16 \mathrm{~m} \mathrm{BGL}$ in pre-monsoon and $2-10 \mathrm{~m}$ in the post-monsoon season. The flowing of groundwater is mainly seen from northwest to southeast, with the hydraulic gradient varying from 1:5 to 1:6 (CGWB 2018; Halder et al. 2021).

The overall climate of this region is humid subtropical in nature. The average annual rainfall is $1700 \mathrm{~mm}, 75$ percent of which is confined during the monsoon season. The temperature here varies from a maximum of $40{ }^{\circ} \mathrm{C}$ in summer and a minimum of $11^{\circ} \mathrm{C}$ in the winter season (Chakraborty 2017). 


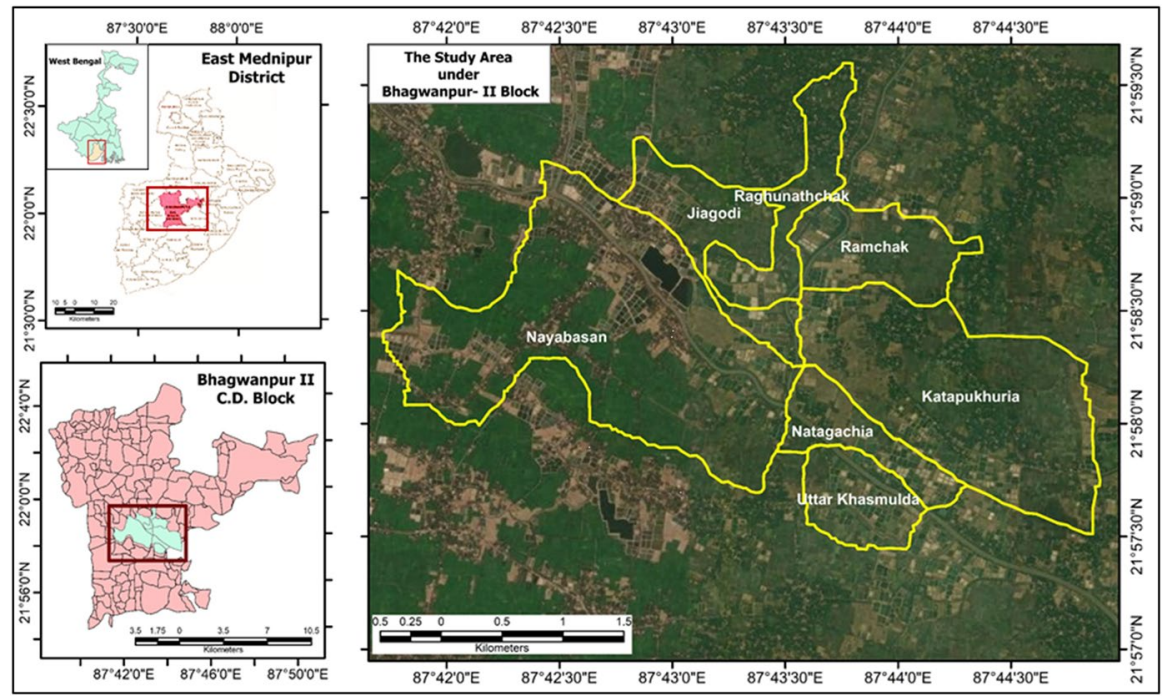

Fig. 1 Location map of the study area

Paddy is the most crucial rainfed crop in the study area. Two types of paddies are cultivated; Kharif for the rainy season and Ravi during the winter, with available irrigational water (Ojha and Chakrabarty 2018). The profitability of paddy and other crops in two seasons is good enough because of the above-mentioned hydro-geological and climatic characteristics in this region. However, presently, the production has become marginal for the aquaculture surrounding agricultural fields due to saltwater intrusion from brackishwater ponds.

\subsection{Sources of materials}

The current study is mainly based on a primary empirical database gathered over the course of a month of intensive fieldwork. In addition to the empirical database, the high-resolution Google Earth Pro-based remote sensing information was also used for developing geodatabase and analyzing the spatio-temporal changes quantitatively. The accuracy and acceptability of the Google-based information were confirmed through comparison with Sentinel 2 multispectral satellite image $(10 \mathrm{~m} \times 10 \mathrm{~m})$ from earth explorer of USGS (https://earthexplorer.usgs.gov/) and actual field information from direct observations at the time of the survey.

The procedure for obtaining google based image information was achieved by following the three steps outlined below,

Step 1: Estimation of accuracy and acceptability of Google Earth image through comparison with actual ground reality.

Step 2: Digitization and interpretation of the Google Earth image

Step 3: Measurement of the area under aquaculture and quantification of the change. 
Further, for assessing the changing dimension livelihoods associated with both activities prevailing in the study area, a total of 100 sample households, 50 agriculturists, and 50 shrimp farmers were surveyed, with a semi-structured questionnaire. Samples were collected using stratified simple random sampling technique. At first, the households were purposively divided into two homogeneous strata (i.e., Agriculturist and Shrimp Farmers) to fulfill the objectives, and thereafter the same number of samples from each stratum were selected randomly. Separately 20 commercial shrimp fishermen and farmers and two key informants from gram panchayat were questioned to learn about the expenses, returns, and other pertinent facts and challenges related to shrimp cultivation. Also, one focus group discussion with 18 rice farmers was arranged after building a good rapport at Uttar Khasmulda village. The focus group discussion was mainly on the issues of agricultural sustainability and profitability. Finally, 50 soil samples were collected randomly to depict the spatial soil salinization and vulnerability problem.

\subsection{Methods}

\subsubsection{Estimation of accuracy and acceptability of Google Earth geodatabase}

In this article, to fulfill the first objective, the confusion matrix has been used to evaluate the accuracy and consistency of the Google Earth pro image over the Sentinel 2 data. The confusion matrix basically explains the ground reality and the actual correctness of the forecast site information (Cui and Shi 2012; Talukdar et al. 2020). With this method, several sites of classified images are compared with the actual corresponding ground through field verification. The extraction of both the LULC from natural color band composite was done using the maximum likelihood technique for supervised classification in the ArcGIS environment.

The comparison matrix can estimate three types of accuracy:

a. Overall accuracy:

$$
\mathrm{OA}=\frac{\sum D}{N},
$$

where OA overall accuracy, $\sum D$ the total no of authentic sites, $N$ total no of sites taken into consideration for confusion matrix.

b. User accuracy:

$$
\mathrm{UA}=\frac{\sum D_{k l}}{C_{1}},
$$

where UA user accuracy, $D_{\mathrm{kl}}$ no. of correctly classified (authentic) sites in lth column, $C_{1}$ total no of sites taken into consideration in lth column.

c. Producer accuracy: 


$$
\mathrm{PA}=\frac{\sum D_{k l}}{R_{k}}
$$

where PA producer accuracy, $D_{k l}$ no of correctly classified sites (authentic) in kth row, $R_{k}$ total no of sites taken into consideration in $k$ th row.

Along with the confusion matrix to extract the exact correctness of the output maps, the Kappa coefficient $(\widehat{K})$ methodology was applied. The value of the Kappa coefficient varies between 0 and 1 . The value 0 indicates no correspondence, and value 1 indicates a perfect correspondence with ground reality (Deng et al. 2019; Rwanga and Ndambuki 2017). The mathematical expression of the kappa coefficient is as follows:

$$
\widehat{K}=\frac{T \sum_{k=1}^{c} D_{k l-\sum_{i=1}^{m} R_{k} \cdot C_{l}}}{l=1 \quad \begin{array}{c}
j=1 \\
T^{2}-\sum_{\substack{k \\
l=1 \\
l=1}}^{R_{k .} C_{l}}
\end{array}},
$$

$\widehat{K}$ Kappa co-efficient, $T$ total number of sample sites, $c$ number of generated classes, $\sum D_{k l}$ sum of correctly classified sites, $R_{k}$ total no. of samples in kth row, $C_{1}$ total no. of samples in lth column.

\subsubsection{Cost and return analysis}

To understand the economics and people's willingness to shift livelihood strategies in the second objective, the Cost-Return analysis of both rice cultivation and shrimp farming was performed (Show 2018; Alemu et al. 2021). Several inputs were used to calculate the cost of production. These expenses are broadly divided into three groups, as follows:

Capital cost: This is the sum of the initial investments. For agriculture, no such capital cost was identified in the study area. However, shrimp farming includes several initial costs like construction pond, development of infrastructure, etc.

Variable cost/operating cost: It includes the ongoing cost of running the activity. Like human and machine labor, the cost of seeds, insecticides, manure, fertilizers, irrigation charges, etc., in the case of agriculture. Similarly, shrimp farm has operating costs like water accumulation, seeds, and feeding, etc.

Fixed cost: Rental value of owned land, land revenue, taxes, depreciation of capital, interest on initial and working capital, etc.

The profitability is then calculated using the following economic formulas:

$$
\begin{aligned}
& \text { Value of Yield (Return }) \\
& =(\text { Main Product } \times \text { Price per unit }) \\
& \quad+(\text { By product } \times \text { Price per unit }) \text { per hectare }
\end{aligned}
$$




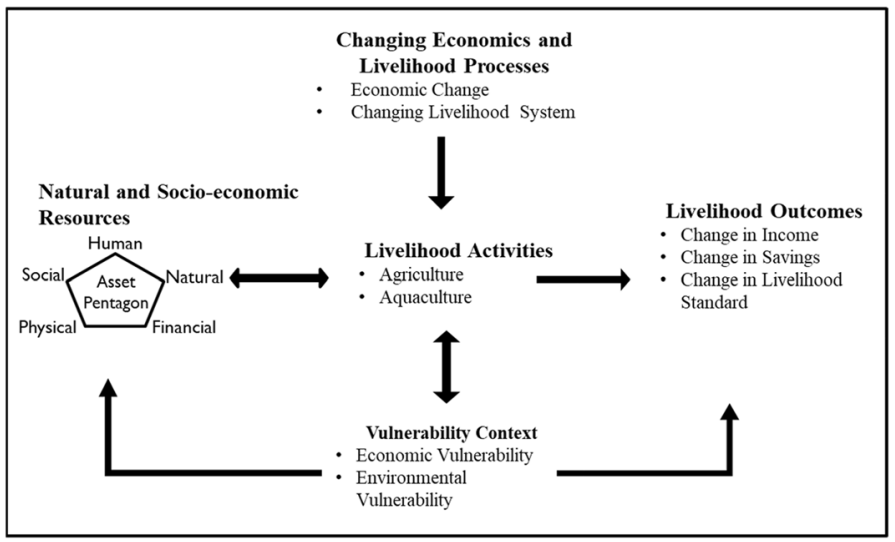

Fig. 2 Modified and simplified conceptual framework of livelihood strategies and outcomes [ adapted from DFID (1999) and modified]

$$
\begin{aligned}
& \text { Net Profit per hectare } \\
& =\text { Value of yield }- \text { Total cost of production } \\
& \quad \text { (Capital Cost + Variable Cost + Fixed Cost })
\end{aligned}
$$

Further, with the help of a partial budget approach between agricultural and shrimp farming, the net gain in profit and opportunity cost was calculated. It basically explains why inhabitants are interested in switching to shrimp farming. The partial budget analysis does not assess profitability; it simply determines the "change in profit" if an alternative is chosen, which can be either positive or negative (Gurmu et al. 2021; Alemu et al. 2021).

The mathematical expression of the Partial Budget approach is

$$
\begin{aligned}
\text { Change in Profit } & =\text { Positive impacts of choosing alternative } \\
& - \text { Negative impacts of choosing alternative }
\end{aligned}
$$

where positive impacts consist of two components: (1) added incomes and (2) reduced costs. Similarly, the negative impacts are under headed by two components: (1) added costs and (2) reduced incomes.

\subsubsection{The sustainable livelihood framework}

The analysis of collected qualitative and quantitative data related to changing livelihood was structured using the sustainable livelihoods framework (Fig. 2). This framework assists in the analysis of diverse livelihood activities in relation to inhabitants' access to capital assets and their vulnerabilities (El et al. 2017; Mistri 2019). As mentioned in the DFID (1999) guidance sheet, 'the SLA framework is the way of thinking about the objectives, scope, and priorities for development to enhance the progress of poverty elimination.' Basically, it attempts to enhance developmental 
policy and practice by understanding the seasonal and cyclical complexity of livelihood alternatives.

There are five core capital assets (Fig 2) in the SLA framework on the basis of which livelihoods are studied (Ahmed et al. 2010; Barnes et al. 2017).

Human capital, viz., the ability to work, knowledge, skills, and good health

Social capital, viz., good social relationships, kinship, social groups, shared values, etc.

Natural capital, the natural resource stock, including water, land, air, forest, and many more

Physical capital, the basic infrastructure, like shelter, energy, transport and communication systems, tools, technologies, and water and sanitation systems.

Financial capital, access to financial services, savings, income, etc.

Among these, some of the assets such as household size (human capital), Education, Age and Experience (most crucial human capital), Landholding and Land Ownership (physical capital), Capital Availability, Income from off-farm, and Access to Credit (Financial Capital), have been considered to understand the accessibility of assets and profit in both the activities in the study area. These assets were selected because through the field study it has been found that these assets are quite diversified and have a significant capability in determining the profit in both the activities prevailing in the present study location. Thus, the selection of assets to analyze the profit from the activities is very much contextual. Apart from this, the assets like experience have a broader scope in the study area, it can combine the influence of skill, knowledge assets in a particular activity in one umbrella. Similarly, capital availability is the product of income and savings. However, no such social capital was found in the study area, which significantly affects profit.

The impact of these available assets on the income from a specific livelihood activity was examined using the correlation coefficients technique (Pahl-Wostl et al. 2021). The Correlation Coefficient ( $r$ ) was calculated using the following formula:

$$
r=\frac{\sum x_{i} y_{i}-\left(\bar{x}_{i} \cdot \bar{y}_{i}\right)}{\sigma_{x} \cdot \sigma_{y}},
$$

where $r$ is the product-moment correlation coefficient, $x_{i}$ and $y_{i}$ refer to the values of two variables for ith observation, $\bar{x}_{i}$ and $\bar{y}_{i}$ are the means of the two variables and $\sigma_{x}$ and $\sigma_{y}$ are standard deviations of the variables.

To see how far the adopted alternative changed the livelihood opportunities of the previously rice cultivators cum present shrimp farmers, comparisons among past traditional rice and present shrimp farming outcomes were accomplished. The memory retrieval interview method was applied to collect information related to the past livelihood outcomes. The present shrimp farmers were asked to remind their way of living before adopting shrimp farming. The comparisons were further statistically tested using the Analysis of Variance ( $F$-test). Both qualitative and qualitative parameters were compared. Like as a qualitative livelihood outcome parameter, food security has been considered. Food security is a complex and multifaceted topic to 


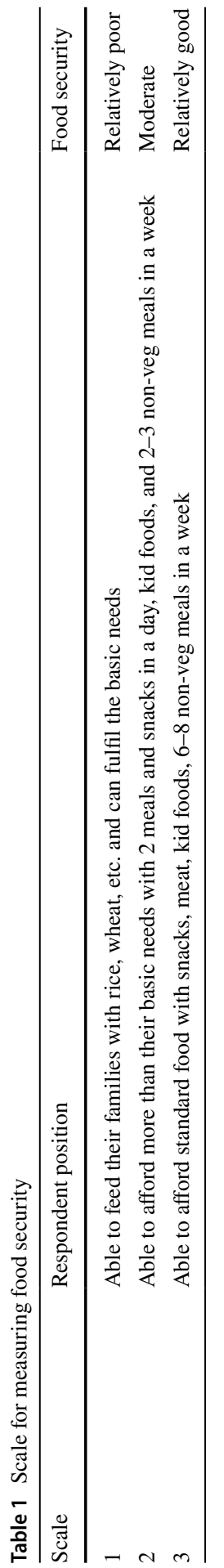


quantify. It has subjective as well as objective implications (Migotto et al. 2008; Na et al. 2015). In this study, we have used this parameter in subjective means mainly based on peoples' perceptions. At the time of the interview, the respondents were asked to share their perception about their food intake and availability for both after and before adopting shrimp cultivation. Several researchers have mentioned the Likert scale as a useful measure for analyzing peoples' perceptions related to food consumption and security (Frewer et al. 1996; Lobb et al. 2007; Na et al. 2015). Similarly, based on the primary conversation with some of the respondents before starting the full-length survey, we have developed a 3-point scale that is very contextual and well fitted in the present context (Table 1).

To assess the vulnerabilities, the gathered people in the focus group discussion of Uttar Khasmulda village were asked individually to identify and rank the negative impacts of adopted alternatives whatever they are facing. Behind this process, the intention was to collect the ground reality by enabling the victims to identify and prioritize their own problems that they are experiencing every day. After that, to validate and address the environmental vulnerabilities (which is the cause behind social vulnerabilities) due to soil salinization, the spatial pattern of soil $\mathrm{pH}$ was mapped using the interpolation (IDW) technique from spatial analyst tools in the ArcGIS environment (Emadi and Baghernejad 2014). The soil samples for $\mathrm{pH}$ mapping were collected randomly at different distances from shrimp farms.

\subsubsection{Finding the coping strategies}

Sequences of responses to crisis are usually referred to as coping strategies (Maxwell et al. 1999). Along with the SLA framework, it is also a useful element in any livelihood study. The coping strategies are the way out to survive in the crisis phase (Ahmed et al. 2010). In the present study, identification of the coping strategies is our third objective. Therefore, during the interviews, the inhabitants were asked about their adopted coping strategies to see how the vulnerable shrimp cultivators manage their livelihood in the crisis phase. After that, the responses were organized using Maxwell et al. (1999) framework for coping strategies. This sequential arrangement was based on two criteria, viz. number of years exposed to losses and the intensity of vulnerability.

\section{Results}

\subsection{Quantification of expansion of commercial shrimp aquaculture}

The shrimp culture in the study area is traditional and semi-intensive to intensive in nature. As per the information provided by the 20 -sample fisheries farm owners, before 2010, only 24 percent of today's installed farms were there. From 2010 to 2015 , the number increased to 82 percent by grabbing agricultural land, and after 2015 the remaining ponds were established. The survey also found that the farmers in the study area are mainly two types; the wealthy farmers, who have sufficient capital, are involved more in commercial shrimp cultivation. 

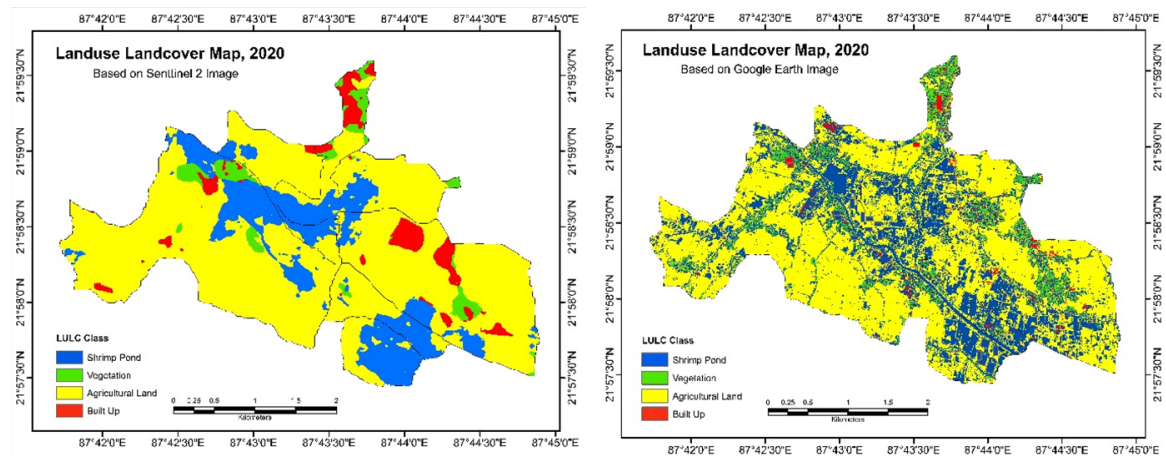

Fig. 3 Landuse landcover maps from Sentinel 2 and Google Earth image

Table 2 Confusion matrix and kappa co-efficient for accuracy estimation of LULC map from sentinel image

\begin{tabular}{llllllll}
\hline LULC class & Shrimp pond & Vegetation & Agricultural land & Built up & Total & $\begin{array}{c}\text { UA } \\
\begin{array}{c}\text { Kappa co- } \\
\text { efficient }\end{array}\end{array}$ \\
\hline Shrimp pond & 44 & 3 & 1 & 2 & 50 & 0.88 & 0.76 \\
Vegetation & 7 & 22 & 2 & 1 & 32 & 0.69 & \\
Agricultural land & 5 & 0 & 45 & 0 & 50 & 0.90 \\
Built up & 2 & 1 & 2 & 12 & 17 & 0.71 \\
Total & 58 & 26 & 50 & 15 & & & \\
PA & 0.76 & 0.85 & 0.90 & 0.80 & & & \\
OA & 0.82 & & & & & & \\
\hline
\end{tabular}

They might not have their land, but they used to take land from marginal farmers against a fixed price (1600-2200 USD/ha) per annum. Whereas the marginal farmers have less share in the conversion. Moreover, a significant part of them is engaged in traditional rice cultivation, and they do not want to convert their land. However, some of them are converted their land into fisheries. But the production is subsistence type in such cases. It has also been found from the survey that the maximum fisheries farm owner has around 0.8 hectares of land invested in aquaculture. While 26 percent of them have more than 0.8-hectare land, but in such cases, a significant portion is borrowed leased land, and the maximum frequency, i.e., 36 percent of shrimp farm owners, have taken greater than equals to 0.53 hectares of leased land.

The information collected from the field survey is not enough to quantify the exact change in land use. Thus, remote sensing technology coupled with GIS is used for generating the geodatabase to identify the land-use change (Dutta et al. 2016). However, while monitoring the mushrooming growth of minute surface features like aquaculture farms here, coarse resolution multispectral Landsat data may not be a good selection, as these kinds of minor features are not 
Table 3 Confusion matrix and kappa co-efficient for accuracy estimation of LULC map from Google Earth Image

\begin{tabular}{llllllll}
\hline LULC class & Shrimp pond & Vegetation & Agricultural land & Built up & Total & $\begin{array}{c}\text { UA } \\
\text { Kappa co- } \\
\text { efficient }\end{array}$ \\
\hline Shrimp pond & 48 & 0 & 2 & 1 & 50 & 0.96 & 0.85 \\
Vegetation & 0 & 29 & 0 & 3 & 32 & 0.91 & 0.86 \\
Agricultural land & 7 & 0 & 43 & 0 & 50 & 17 & 0.82 \\
Built up & 2 & 1 & 0 & 14 & & & \\
Total & 57 & 30 & 45 & 0.82 & & & \\
PA & 0.84 & 0.97 & 0.96 & & & & \\
OA & 0.89 & & &
\end{tabular}

Table 4 Growth of brackish water shrimp ponds during 2010-2020

\begin{tabular}{|c|c|c|c|c|c|c|c|}
\hline \multirow[t]{3}{*}{ Villages } & \multirow{3}{*}{$\begin{array}{l}\text { Total vil- } \\
\text { lage area } \\
\left(\mathrm{Km}^{2}\right)\end{array}$} & \multicolumn{6}{|c|}{ The area under shrimp aquaculture } \\
\hline & & \multicolumn{2}{|l|}{2010} & \multicolumn{2}{|l|}{2015} & \multicolumn{2}{|l|}{2020} \\
\hline & & $\mathrm{Km}^{2}$ & Percentage & $\mathrm{Km}^{2}$ & Percentage & $\mathrm{Km}^{2}$ & Percentage \\
\hline Nayabasan & 4.2335 & 0.061994 & 1.46 & 0.677992 & 16.01 & 1.1321 & 26.74 \\
\hline Jiagodi & 1.0542 & 0.013002 & 1.23 & 0.198581 & 18.84 & 0.299256 & 28.39 \\
\hline Kata Pukhuria & 2.8992 & 0.049452 & 1.71 & 0.258998 & 8.93 & 0.263407 & 9.09 \\
\hline Natagachia & 0.5551 & 0.043291 & 7.80 & 0.126851 & 22.85 & 0.217884 & 39.25 \\
\hline Raghunath Chak & 0.8084 & 0.016863 & 2.09 & 0.109227 & 13.51 & 0.22096 & 27.33 \\
\hline Ram Chak & 0.6801 & 0.026444 & 3.89 & 0.159796 & 23.50 & 0.278519 & 40.95 \\
\hline Uttar Khasmulda & 0.5541 & 0.153455 & 27.69 & 0.270265 & 48.78 & 0.304016 & 54.87 \\
\hline
\end{tabular}

Source: estimated by the researcher from google earth imagery
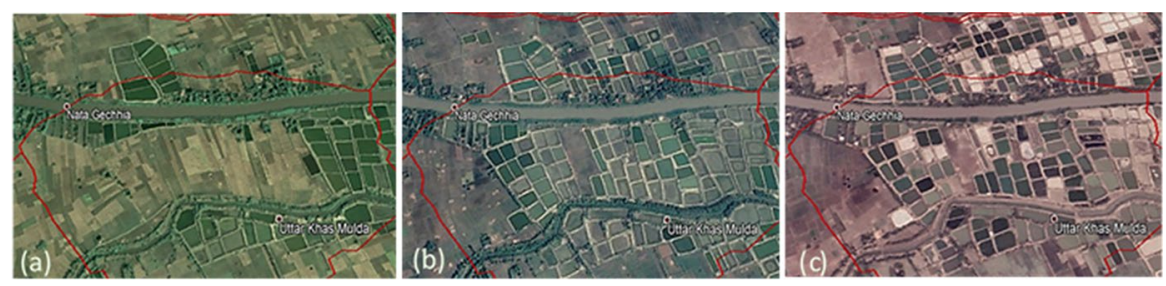

Fig. 4 The spatio-temporal changes in brackish waterbodies. a 2010, b 2015, and c 2020

easily discernible in the images (Dutta et al. 2016). Moreover, the Sentinel 2 satellite database cannot accurately predict these farms/ ponds because many of these farms in this study area have a lower area than its spatial resolution (i.e., $10 \mathrm{~m} \times 10 \mathrm{~m}$ ). Thus, the only way to extract such minute details and quantify the conversion process without spending any money is to use publicly accessible mufti-temporal Google Earth images (Freitas et al. 2011; Dutta et al. 2016). To examine this argument and establish the acceptability of the Google Earth images 
Fig. 5 Village wise temporal change in areal expansion. Source: estimated by the researcher
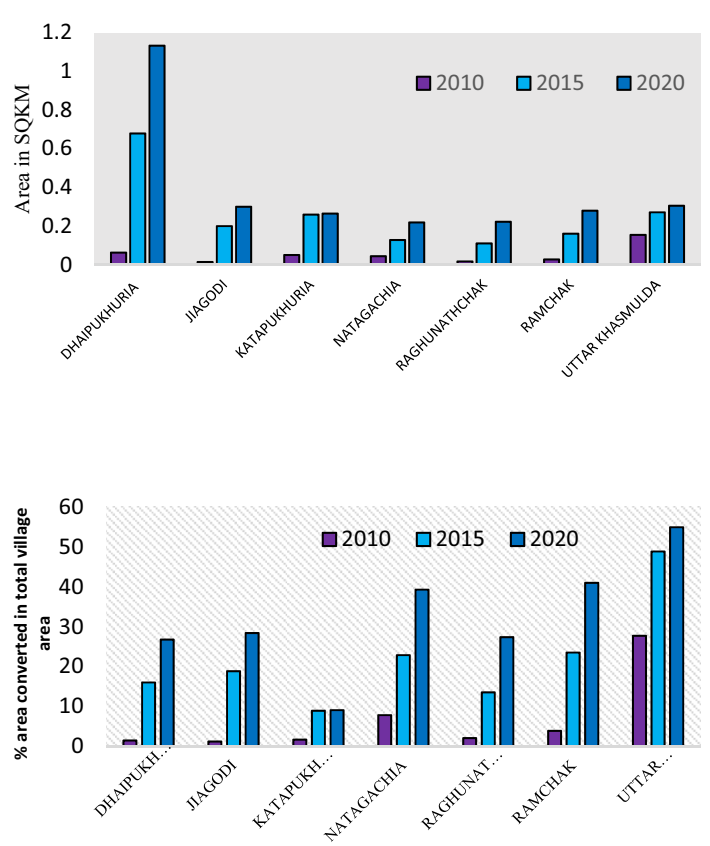

Fig. 6 Temporal change in village wise percentage area coverage. Source: estimated by the researcher

at the very first step comparison of predicting capability between land use land cover map based on Sentinel 2 satellite data (Fig. 3) and Google Earth land use land cover data (Fig. 3) was performed. The results showing Google Earth imagebased land use land cover map has an overall accuracy of 89 percent (Table 3), which is better than the sentinel-based map with an overall accuracy of 82 percent (Table 2). The estimation of the kappa coefficient also confirms the same (Tables 2, 3).

The spatial statistics obtained from the Google Earth image of 2010 (Table 4) evident that the study area had only $0.37 \mathrm{sqkm}$ area of total $10.8 \mathrm{sqkm}$ test area converted into brackish water ponds (Fig. 4). Six of the seven study villages had minimal conversion (approx. 5 percent of total village area). Nevertheless, Uttar Khasmunda village, which is situated in the southeast of the area under study, had an effective conversion. About 28 percent of the total village area is under shrimp fisheries. In 2015 the fisheries pond coverage of the study area increased to $1.80 \mathrm{sqkm}$, and finally, in 2020, around $2.76 \mathrm{sqkm}$ area got converted into brackish water ponds.

After quantifying the Google Earth geodatabase (Table 3), it has also been found that the growth was more prominent in Nayabasan (urf Dhaipukhuria) village. The total shrimp pond area was just $0.06 \mathrm{sqkm}$ in 2010, but in 2020, it increased to $1.03 \mathrm{sqkm}$ (Fig. 5), which covered 24 percentage of the total village area. At the same time, the Uttar Khasmulda village had a low growth rate in respect of other villages. But the amount of change in percentage converted land has been found maximum here in terms of total village area (Fig. 6). Sixty percent of the total area of Uttar Khasmulda village 
is now converted to shrimp aquaculture. In contrast, Katapukhuria had experienced less conversion. Only 9 percent of the entire village area invested in shrimp cultivation.

The obtained satellite database (Table 4) also displayed that the conversion rate was about 21 percent per annum from 2010 to 2015, and after that, it declined to 14 percent per annum.

\subsection{Changing economics and livelihood sustainability}

As found in the field, the inhabitants of the study area are divided into two groups, the traditional rice cultivators and shrimp farmers, and most rice cultivators are small to moderate landholders. In contrast, the farmers with large land have converted or are interested in converting their land into fishery farms (shrimp culture).

\subsubsection{Economics of agriculture and aquaculture}

The cost return analysis for both rice cultivators and shrimp farmers was performed based on the information provided by the respondents in the study area. In rice cultivation, no such capital initial investment is found. However, as operating cost, farmers have invested a sum of 1950 USD/ha in the Rabi and Kharif season of 2019. Apart from this operating variable cost, there was a fixed cost of 470 USD /ha. In return, farmers got 4036 USD, including the return from plant product (straw). Thus, the net profit they had was 1617 USD/ha in 2019 (Table 5).

Whereas in shrimp cultivation, the average investment for developing the initial infrastructure of 1 hectare of land was found around 17,612 USD for the year 2019, and after the infrastructure became suitable for cultivation, the farmers again reinvested approx. - 30,000 USD as operating cost for one crop period of shrimp (Table 6). In return, the pond had produced an average of 12.78 tons of shrimp for marketing, with 30 seeds $/ \mathrm{m}^{2}$ stocking density and 65 percent survival rate in a 1-hectare pond. The average weight, in that case, was around $35 \mathrm{~g}$ per piece of white leg shrimp, and finally, the net profit the farmer earned was 7216 USD in the year 2019 (the selling price was 3.70 USD). The farm owners also mentioned in a normal year, if everything goes normal without any pollutant hazards and diseases, they can cultivate three consecutive cropping seasons as the harvesting period is very low (only 120 days). The partial budgeting of these two different activities in the study shows positive (+6400 USD/year) differences (Table 7), which means the adaptation of the shrimp cultivation increased the overall income of the inhabitants.

\subsubsection{Livelihood strategy in agriculture and aquaculture}

Based on the collected dataset, a comparative analysis for agriculture-aquaculture livelihoods has been performed. In terms of land investment, capital participation, labor engagement, and profit, the obtained data and analysis show a statistically significant difference $(p<0.01)$ between these two sectors (Table 8). 


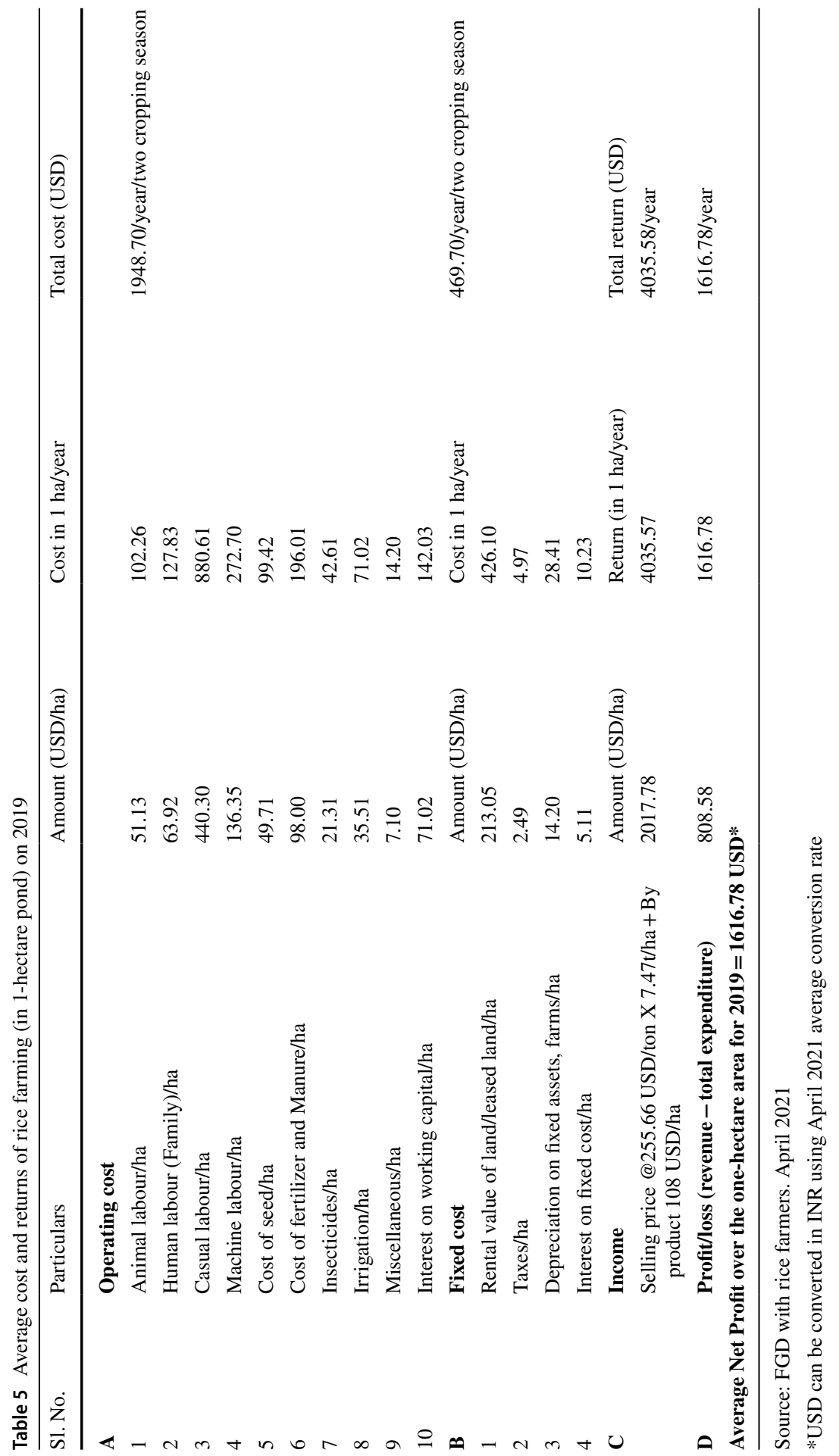


Table 6 Average cost and returns in shrimp culture (in 1-hectare pond) on 2019

\begin{tabular}{|c|c|c|c|}
\hline Sl. No. & Particulars & Cost in $1 \mathrm{ha} /$ one time & Total cost (USD) \\
\hline $\mathbf{A}$ & Capital & & \\
\hline 1 & Construction of pond & 4774.46 & 17612.44/One time \\
\hline 2 & Inlet and outlet structure of pond, & 2652.48 & \\
\hline 3 & Pumphouse cum workshop & 1060.99 & \\
\hline 4 & Watchman shed & 636.59 & \\
\hline 5 & Pumps (1.5 HP X 8) & 2652.48 & \\
\hline 6 & Aerators (1 HP) with accessories, 30 Nos & 4243.96 & \\
\hline 7 & Electric installation with electrification & 530.50 & \\
\hline 8 & Land and farm equipment & 1060.99 & \\
\hline B & Operating cost & Cost in 1 ha/year & 100581.91/3 Crops/year \\
\hline 1 & Water accumulation cost & 3023.82 & \\
\hline 2 & Chemicals and manure @ Rs.90,000/ha & 3819.57 & \\
\hline 3 & Cost of seeds@Rs.65,000/1 lakh seeds & $19,097.83$ & \\
\hline 4 & Cost of feed @ Rs. 3000/Kg & $47,744.58$ & \\
\hline 5 & Fuel charges & 4774.46 & \\
\hline 6 & Electricity charges & 1909.78 & \\
\hline 7 & Labour charges & 9548.92 & \\
\hline 8 & Medicines & 7957.43 & \\
\hline 9 & Annual maintenance and repairing cost & 2705.53 & \\
\hline $\mathbf{C}$ & Fixed cost & Cost in 1 ha/year & 16519.62/year \\
\hline 1 & Decrementation of capital cost @ 20\% & 3182.97 & \\
\hline 2 & Establishments cost/year @ 15\% & 2705.53 & \\
\hline 3 & Total loan interest & $10,631.13$ & \\
\hline \multirow[t]{2}{*}{ D } & Income & Return in 1 ha/year & Total return (USD) \\
\hline & $\begin{array}{l}\text { Selling price @ } 3.70 \text { USD } / \mathrm{kg} \text { in } 2019 \\
\text { (Average stocking density=30 Nos. Seed/ } \\
\mathrm{m} 2 \text { then, } 30 \text { X } 2508=75,240, \text { Survival @ } \\
65 \%=48,906 \text { and Total biomass }=48,906 \\
\text { X } 35 \mathrm{gm}=1,711,710 \times 7.47(1 \mathrm{ha}=7.47 \\
\text { bigha in WB) }=12,786,473.7 \text { X } 3 \\
\text { times }=38,359.42 \mathrm{~kg}\end{array}$ & 141929.85 & 141930/year \\
\hline $\mathbf{E}$ & Profit/loss (revenue - total expenditure) & 7216.03 & 7216/year \\
\hline \multicolumn{4}{|c|}{ Average Net Profit over one hectare area for $2019=7216$ USD $*$} \\
\hline
\end{tabular}

Source: Interview with shrimp farm owners. March 2021

*USD can be converted in INR using April 2021 average conversion rate

The average land investment in the agriculture sector is more or less 0.31 ha, wherein shrimp farming, it is near about 0.8 ha. But for 90 percent of shrimp farmers, a major portion of the invested land is occupied by leased land. The survey has identified that the average size of taken leased land is 0.54 ha. In both, the sector the harvesting tenure is quite the same, but there is a significant difference in the frequencies of crop season in a year. The agriculture of this region is characterized by monsoonal rainfed crops; in some of the regions, people grew different crops in 
Table 7 Partial budget analysis between rice and shrimp cultivation

\begin{tabular}{|c|c|c|c|c|c|}
\hline \multicolumn{3}{|c|}{ Positive impacts of adopting shrimp farming } & \multicolumn{3}{|c|}{ Negative impacts of shrimp cultivation } \\
\hline $\mathbf{A}$ & $\begin{array}{l}\text { Income generated by } \\
\text { adopting shrimp farming }\end{array}$ & & $\mathbf{A}$ & $\begin{array}{l}\text { Costs of adopting the } \\
\text { shrimp cultivation }\end{array}$ & \\
\hline \multirow[t]{3}{*}{1} & Increased income & 137894.43 & 1 & Adding capital cost & 17612.44 \\
\hline & & & 2 & Increased operating cost & 98633.21 \\
\hline & & & 3 & Increased fixed cost & 16049.92 \\
\hline \multirow[t]{3}{*}{ B } & $\begin{array}{l}\text { Costs saved by adopting } \\
\text { the shrimp farming }\end{array}$ & 2418.40 & B & $\begin{array}{l}\text { Income loss after movin } \\
\text { from agriculture }\end{array}$ & \\
\hline & & & & Lost income & 1616.78 \\
\hline & Total positive impacts & 140312.8 & & Total negative impacts & 133912.4 \\
\hline
\end{tabular}

*USD can be converted in INR using April 2021 average conversion rate

Table 8 Comparative information about different livelihoods strategy

\begin{tabular}{lll}
\hline Information & Agriculture $n=50$ & $\begin{array}{l}\text { Shrimp Aquaculture } \\
n=50\end{array}$ \\
\hline Average land investment (hectare) & & $0.8032 \pm 0.38$ \\
Processing period (weeks) & $15-16$ & $16-17$ \\
Capital investment (USD)/ha & 0 & $17,209 \pm 1345$ \\
Labour/ha & $123 \pm 17$ & $8 \mathrm{p}+22 \mathrm{t}^{*}$ \\
Frequency Cultivated/year & 2 & 3 \\
Expenditure (USD)/ha/one crop & $1128.63 \pm 225.8$ & $40215.84 \pm 932.5$ \\
Income (USD)/ha/one crop & $1808.18 \pm 303.66$ & $44951.21 \pm 1552.8$ \\
Profit (USD) & $704.45 \pm 97.61$ & $2278.7 \pm 489.95$ \\
Amount of leased land (ha) & - & $0.54 \pm 0.33$ \\
\hline
\end{tabular}

$p$ permanent, $t$ temporary

Source: Field Survey, March-April, 2021

the winter season with irrigation water. But spatial crop patterns are majorly affected by the monoculture of paddy. In comparison, shrimp farmers can harvest three times a year. In each harvesting season, with an investment of 40,215 USD, the profit they have is more than three times larger than the average profit from traditional agriculture (i.e., 704.45 USD).

\subsubsection{Asset accessibility and profit opportunities}

The agriculturists' capital investment and off-farm income have been determined to have no relationship with profit among the several important assets or capitals available in the study area (Table 9). Credit availability, farmer age, education, and land ownership all show a moderate to weak association. In turn, there is a significant 
Table 9 Asset accessibility and profit opportunities of two groups

\begin{tabular}{llc}
\hline Livelihood assets & $\begin{array}{l}\text { Household income (correlation coef- } \\
\text { ficient) }\end{array}$ \\
\cline { 2 - 3 } & Agriculture & Shrimp aquaculture \\
& $n=50$ & $n=50$ \\
\hline Household size & $0.41^{* *}$ & $0.82^{* * *}$ \\
Education & $0.28^{* *}$ & $0.73^{* * *}$ \\
Age & $0.46^{*}$ & $0.22 \mathrm{~ns}$ \\
Capital investment & $0.03^{\mathrm{ns}}$ & $0.45^{* *}$ \\
Experience & $0.57^{* * *}$ & $-0.72^{* * *}$ \\
Land holding & $0.87^{* * *}$ & $0.83^{* * *}$ \\
Access to credit & $0.34^{*}$ & $0.70^{* *}$ \\
Land ownership & $0.27^{*}$ & $0.69^{* *}$ \\
Off-farm income & $0.09 \mathrm{~ns}$ & $0.38^{*}$ \\
\hline
\end{tabular}

Source: Field Survey, March-April 2021

$* * *$ Significant at $1 \%$ level

$* *$ Significant at $5 \%$ level

*Significant at $10 \%$ level

${ }^{\text {ns }}$ Not significant

positive association between landholding $(r=0.87)$ and agriculturist income $(r=0.87)$, with years of experience accounting for $1 \%$ of the variation and household size accounting for $10 \%$ of the difference.

In contrast to agriculturists for the shrimp farmers, it has been found that the profit coefficient is moderate to strongly related to capital investment, land ownership, credit access, education, household size, and landholding. However, age has no such influence on the profit, and only the years of experience have a strongly negative relationship accounting for 1 percent variance. The correlation coefficient values clearly indicating to the fact that in shrimp farming, people use their available assets more efficiently than the agricultural farmers and achieve a better profit. However, with increasing years of establishment, the profit stated decline significantly. In the later part of this paper, vulnerability issues have been discussed elaborately. Notably, from the key informant interviews, it has been found that in the case of shrimp farmers, the size of landholding means how much land they invested in the cultivation (own + leased), and the number of working educated members of the household are the key determinants of profit. During our conversation, the panchayat officials also noted that experienced shrimp farmers with sufficient wealth are more likely to choose leased land to keep themselves safe (KII).

\subsubsection{Changing livelihood outcome with adopting shrimp farming}

The present study has also been tried to quantify the changed livelihood outcome for the shrimp farmers (Table 10). It has been found through the ANOVA test that 
Table 10 Changing livelihood outcomes after adopting shrimp farming

\begin{tabular}{lll}
\hline Household particulars & $\begin{array}{l}\text { Before } \\
\mathrm{n}=50 \\
\text { Mean } \pm \mathrm{SD}\end{array}$ & $\begin{array}{l}\text { After } \\
\mathrm{n}=50 \\
\text { Mean } \pm \mathrm{SD}\end{array}$ \\
\hline Income in USD/month & $145.19 \pm 55.36$ & $384.18 \pm 76.44$ \\
Savings in USD/month & $8.28 \pm 5.31$ & $70.15 \pm 23.98$ \\
land holding (ha) & $0.31 \pm 0.17$ & $0.20 \pm 0.12$ \\
Year of schooling & $6 \pm 3$ & $10 \pm 3$ \\
Family size & $4.22 \pm 1.1$ & $4.1 \pm 1.5$ \\
Food security & Moderate & Good \\
\hline
\end{tabular}

$n$ sample size of shrimp fishers

USD can be converted in INR using April 2021 average conversion rate

except for family size, there is a significant positive change $(p<0.01)$ in livelihood outcomes after adopting shrimp cultivation.

With land-use conversion as an immediate effect, the livelihood strategy started developing. The establishment of shrimp farms led to a sharp shift in the mean income of the household (Fig. 7). Previously, more than 27 percent of respondents were in the lowest (710-1420 USD) income group, but it reduced to 10 percent after adopting aquaculture. However, these two response curves follow the same pattern at higher income levels. The study also found some positive changes in the saving pattern along with the income. Around 20 percent of people now have a minimum saving of 568 USD/annum (Fig. 8). The savings graph is quite the same as income. More than 18 percent of respondents were in the lowest considered savings group, but after adopting shrimp, the percentage was reduced by 8 percent. Along with the increasing income and savings, the survey also identified that present shrimp farmers have better health conditions. They have more household assets, amenities, and an excellent social status than their past traditional society.

\subsubsection{Vulnerability context in shrimp farming}

Apart from all previously mentioned immediate positivity towards the livelihood betterment, the agricultural land conversion is further affected by the vulnerability in the long run. The inhabitants of Uttar Khasmulda village individually identified and ranked the vulnerabilities and negative impacts of shrimp culture (Fig. 9). The harshest one they mentioned is the degradation and salinization of the surrounding cropland area, which resulted in unemployment and migrationrelated problems for the inhabitants. After analyzing all the facts and experiences, the study has found two major issues related to land conversion's long-term vulnerability:

a. Inconsistency in production. 


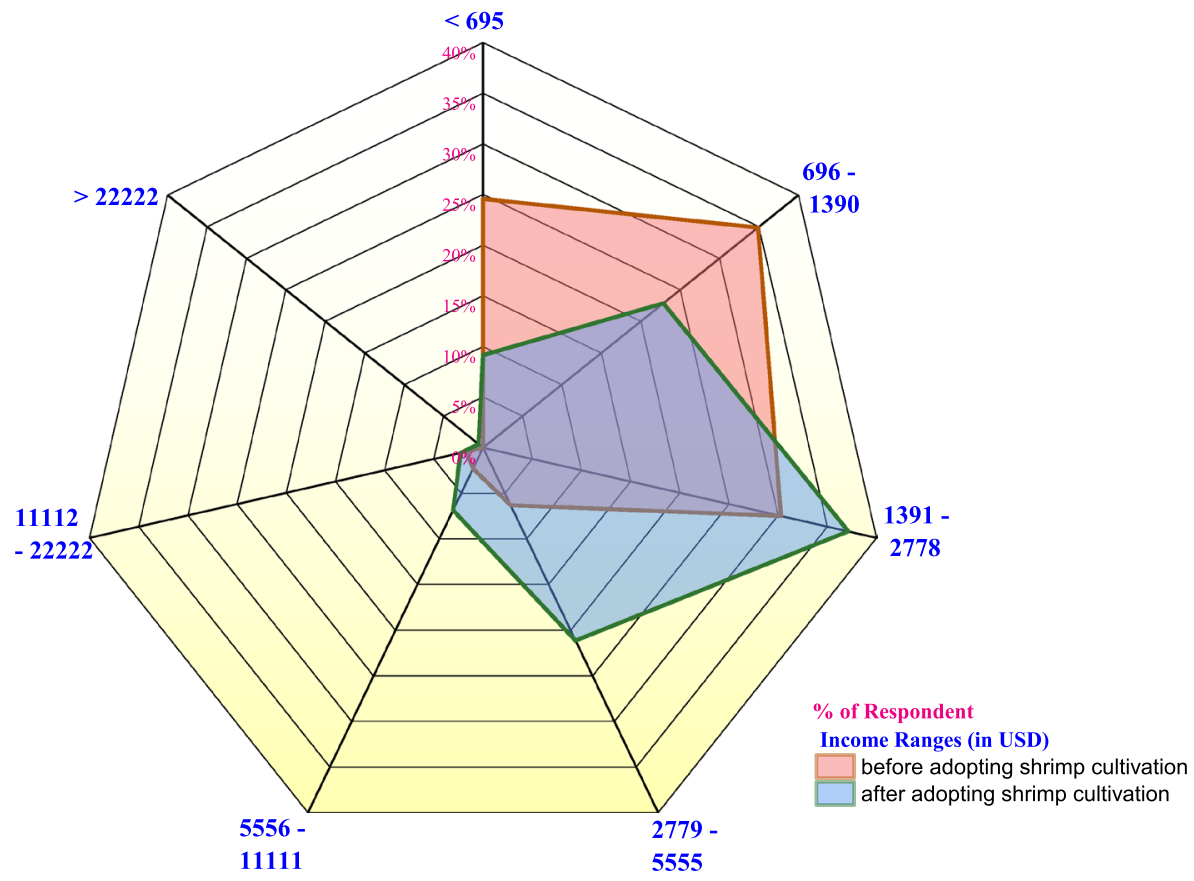

Fig. 7 Changing pattern of income after adopting shrimp culture, Source: Field survey, March-April 2021

It is found that the productivity and the profitability follow an 'inverted U' shaped curve (Fig. 10). After 4-5 years of establishment, productivity starts declining, and about 10-12 years of intensive use made the profitability marginal/ almost zero.

a. Vulnerability for surrounding agricultural land.

The produced spatial pattern map shows that for 90 percent of surrounding agricultural lands, $\mathrm{pH}$ fluctuates from 7.5 to 8.5 (Fig. 11). Moreover, the map shows that the entire region is affected by saltwater inclusion. The $\mathrm{pH}$ value fluctuates from 6.0 to 9.5 , which is relatively high for agricultural activities.

Apart from the evidence of soil $\mathrm{pH}$ distribution, in the focus group discussion held on April 18, 2021, at Khasmulda/Uttar Khasmulda village, the participants mentioned that

“........we become landless and jobless because of the shrimp aquaculture.

Our agricultural land got affected by the neighboring shrimp pond. The productivity becomes marginal due to salinization. We opposed it several times, but shrimp farmers are elites; they had political backup. They are illegally doing most of the things against the government's standard protocol, with no 


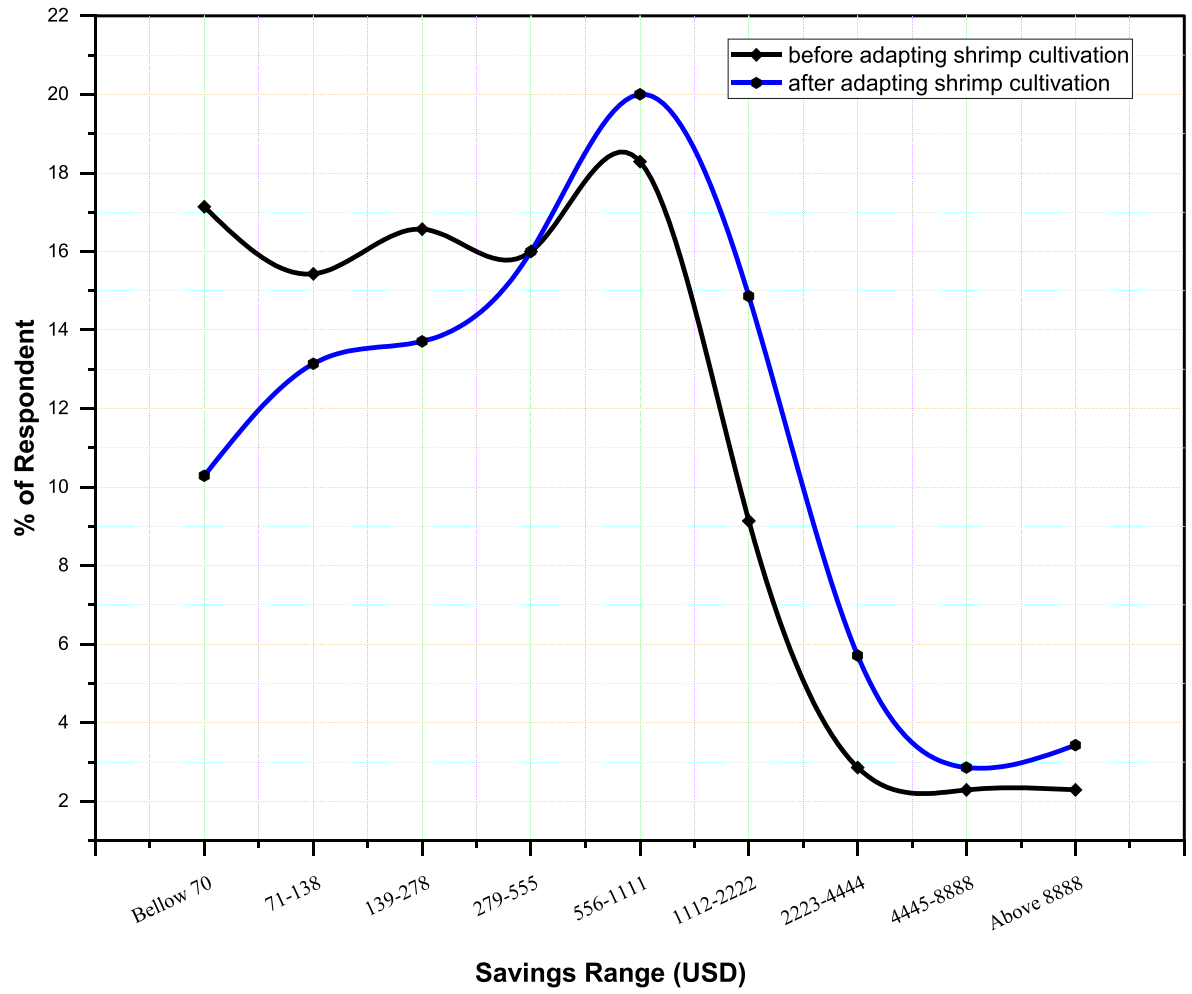

Fig. 8 Changing pattern of savings for the shrimp farmers, Source: Field Survey, March-April 2021

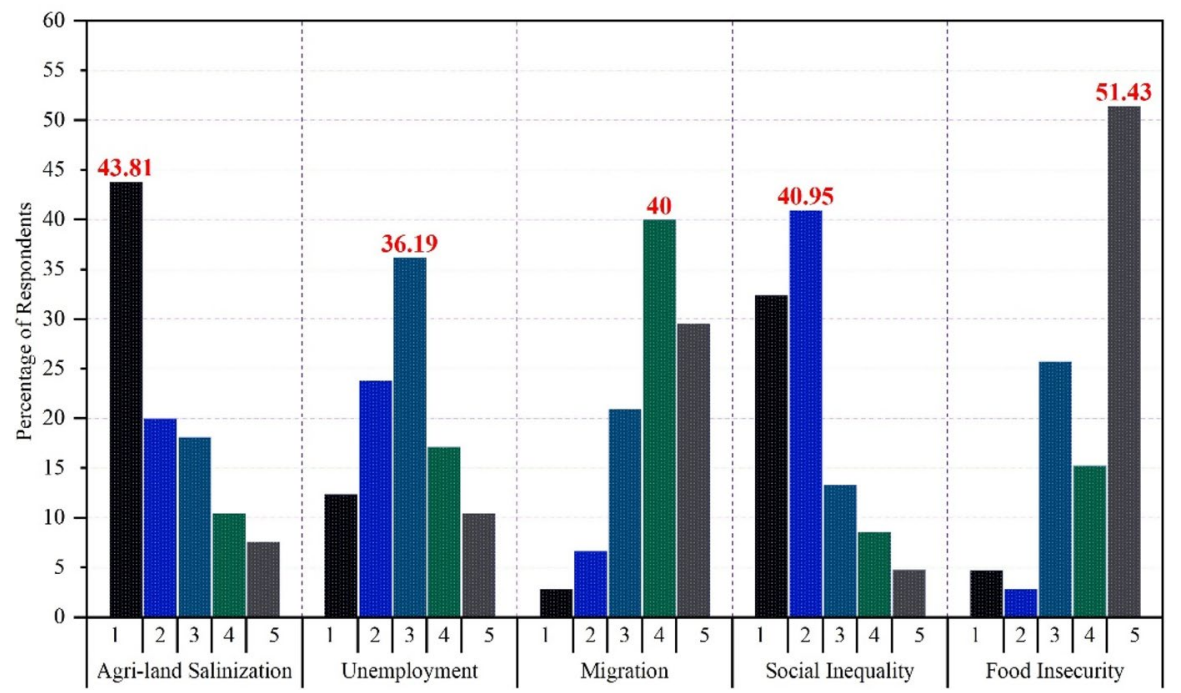

Fig. 9 Impacts of land conversion (ranking based on people's perception), Source: FGD, April 2021 


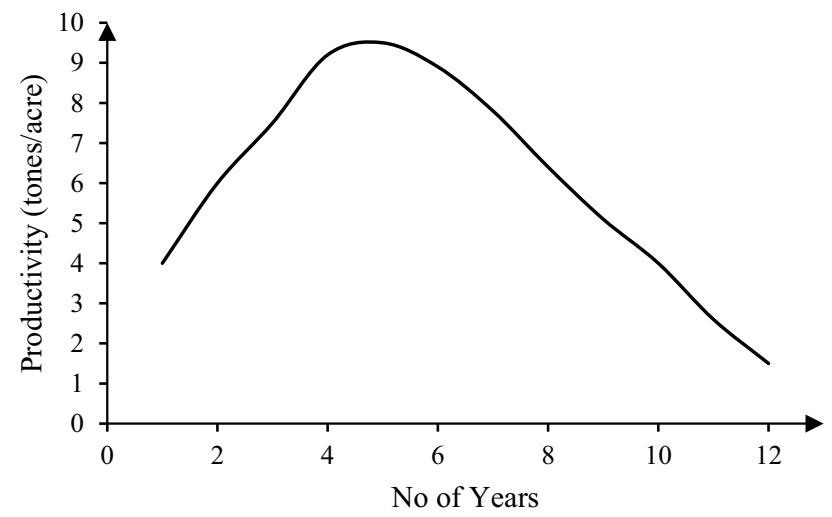

Fig. 10 Differences in productivity with the increasing no of years. Source: FGD and direct observation

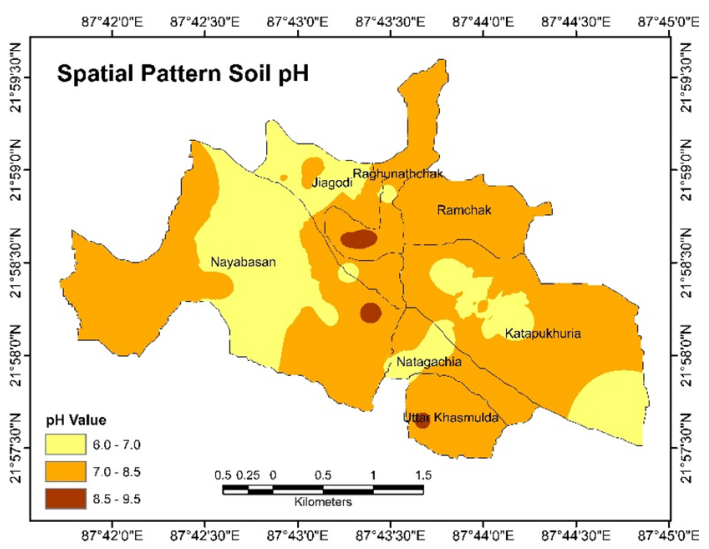

Fig. 11 Spatial pattern of soil $\mathrm{pH}$ in the study area, Source: collected filed samples

buffer zone and barrier around the pond. We, the poor small farmers, have no other choice left and have to give our to the shrimp farm owner at lease." (Medium of Conversation was Bengali).

Ranajit Bera, a shrimp farm worker, when talking about his experience, narrated that,

“......... in 2012, my neighbor's landowner had started shrimp cultivation. However, I did not have enough money at the moment to invest in artificially converting my property. Furthermore, I reasoned that shrimp production would not be lucrative with the little land I had since I would not be able to maintain it in the future, so I opted to pursue rice farming that I used to do earlier. But after 1.5 to 2 years, rice production started decreasing, and I could not feed my family three times a day. Then I gave my land at lease against Rs 
35,000/bigha and started working as paid labor in shrimp farm, some part of which is established in my own land." (Group discussion, April 18 2021, the medium of conversation was Bengali).

\subsection{Coping strategies}

The inhabitants informed that they prefer low-cost food materials most in conserving scarce resources. Other adopted coping mechanism includes taking out a loan, selling livestock, selling off their land, and distress migration. The different adopted coping strategies of the respondent were then arranged sequentially following their exposer to the vulnerability and number of years in stress or loss (Fig. 12) (Maxwell et al. 1999; Ahmed et al. 2010). One good thing that we found during the survey is that a considerable percentage of respondents stated that large commercial shrimp farms employ a considerable number of skilled men and women as daily wage maintenance labor or in freezing, packaging, and marketing of the shrimp product. It helps some of the small-scale exhausted shrimp farmers to maintain their livelihood.

\section{Discussion}

The findings from this study clearly identify that the study area is experiencing a significant occupational shift and depeasantization in search of greater economic return and better quality of life. A significant portion of rice farmers converted their agricultural land, and many more are interested in adopting shrimp culture in the future. The pace of transformation in the study area for the last decade exactly supports what some of the studies predicted earlier (Duarte et al. 2007; Merino et al. 2012; Dutta et al. 2016). The high resolution and contextually acceptable Googlebased remote sensing data physically confirm the same. However, the spatial conversion pattern is highly biased towards the region with a well-connected canal

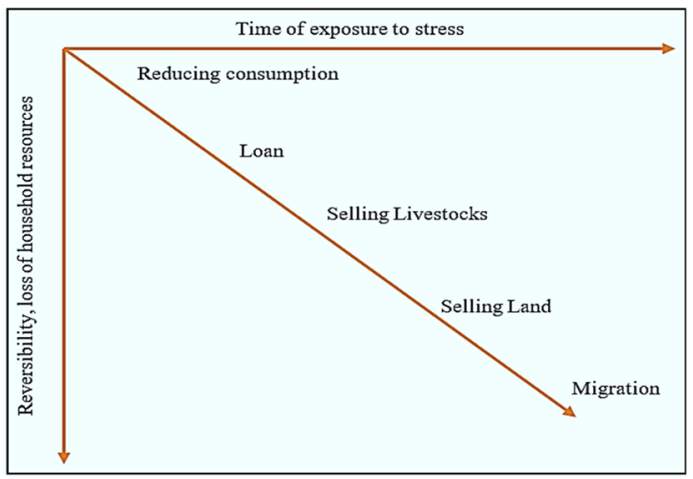

Fig. 12 Simplified coping strategies by landless jobless farmers (modified and adapted from Ahmed et al. 2010) 
system that supplies the massive demand for water in brackish water artificial shrimp production (Pattanaik 2000; Musa et al. 2020). This is why the south-eastern part (Uttar Khasmulda Village) of the study area first experienced the conversion, and since 2006 this region has transformed tremendously in contrast to the whole study area. Indeed, conversion is happening more or less rapidly in the entire study region. But when the conversion rate is considered, surprisingly, it has decreased from 21 percent in 2010-2015 to 14 percent in the recent 5 years. In response to this decrease, the fisheries owners confirm that a substantial number of them had halted conversion expansion due to the experienced vulnerabilities (Field Survey, April 2020). It undoubtedly pointed to the sort of awareness among the residents of their surroundings.

When the question comes to the livelihoods, the study depicts statistically significant positive differences in the livelihoods system associated with shrimp cultivation over the traditional rice cultivation (Islam and Tabeta 2019; Adams et al. 2020). The positive difference in the livelihoods of the inhabitants is mainly because of increasing economic profitability and flexibility (Adams et al. 2020; Nguyen et al. 2021). The findings confirm that the profit of shrimp farmers is more than three times larger than the profit from traditional agriculture, and it is the accelerating factor behind the inhabitant's intentional shift from conventional rice cultivation. However, the conversion is a matter of substantial initial investment for establishing infrastructure, which restricted involvement from each sector of society in the study area.

Some of the studies found that shrimp cultivation is profitable if engagement of land is high and the farmers with large landholding are mainly engaged in this activity (Primavera 1997; Ojha and Chakrabarty 2018; Faysse et al. 2020). However, the present study has found quite different findings in this regard. It shows the capital-intensive artificial shrimp farming is adopted mainly by the wealthy inhabitants of the study area. The inhabitants who have enough capital and can bear the risk are earning huge money by involving in commercial aquaculture. In contrast, marginal farmers with small land and capital doing agriculture with traditional crops and become poorer (Rajarshi and Santra 2011; Ojha and Chakrabarty 2018). Thus, inhabitants are essentially divided into two conflicting groups. The findings suggest that the shrimp farmers in the study are using their available assets more efficiently and achieving a better profit cum quality of living.

Remarkably the positive outcomes from shrimp are not viable. In a few years, the harvesting is becoming minimal, mainly because of the unlawful and intensive aggression of the farmers towards the enormous accumulation of wealth. Studies also have mentioned that the invested land cannot be reformed for any other use (Rajarshi and Santra 2011; Adnan 2013; Maiti 2019; Maity 2019; Rajakumari et al. 2020). This study also found the same consequences. But, here, the problem is more prominent. Because the wealthy farmer majorly adopts artificial shrimp cultivation with the borrowed land, and the wasted land badly affects the lease giving farmers. They are becoming the victim of landlessness and joblessness. While, after giving the degraded land back to their owners, the wealthy shrimp farmers again start searching for new lands. Their capitalistic commercialization generally follows a "Waste and Move" pattern and will gradually convert the entire agricultural 
landscape into an utterly degraded wasteland. As most farms in the study area are very recent, this problem is not prominent yet but an emerging type.

The artificial conversion-led soil salinization problem is another major issue in the inland aquacultural region (Rajarshi and Santra 2011; Ojha and Chakrabarty 2018). In the present study area, most of the aquacultural farms are frequently positioned with agricultural lands and created illegally without following government SOPs. ${ }^{2}$ Thus, the problem of saline water overflows in rainy seasons badly affects the available soil nutrient balance and productivity in surrounding agricultural land. To confirm the soil salinization, the spatial pattern of soil $\mathrm{pH}$ is mapped using interpolation technique, and the result indicates the saltwater intrusion led worst alkane characteristic of the study area.

Furthermore, the environmental-led societal vulnerabilities can be summaries in the following way -

a. Breakdown of traditional livelihood support system:

When it was an agricultural landscape, they could manage their food, fodder for livestock, and other essential elements of their own needs from their fields. They used to get necessary nutritional vitamins added to milk, egg, meat, etc., from their livestock (field survey, April 2021). But after giving land to the fishery or converting it to the saltwater pond, they have lost their confirmed source of food and fodder. It increases their overall expenditure and market dependency for food and other things. If the land is at lease, then those landowners' position becomes worse because their path of extra income by doing multiple activities has been sealed against a fixed price. In such cases, the farmer became jobless or became a distressed migrant laborer. Ultimately the whole process transforms the traditional self-sufficient society into a dependent and imbalanced rural community.

b. Emerging new socio-economic stratification:

The spreading of commercial fishery farming leads to an unequal, polarized socioeconomic stratification in the study area. As discussed earlier, people who are already rich enough become richer. In contrast, the marginal farmers who have less land or, given that in the lease, face the worst situation by becoming jobless. Apart from this, the study area has a sharp conflict between elites and non-elites (Focus Group Discussion).

Now the question comes to what the households are doing when they are facing such crises and losses. Different studies, including the current one, depict that society uses a combination of coping strategies to maintain a sustainable

\footnotetext{
2 In order to provide harmless and effective technical guidance for shrimp hatchery management, implementation of the Standard Operating Procedures (SOPs) is essential. These are also termed as the control protocol formed by the administration to manage the shrimp farming system. The important instructions are: (1) The design of the water distribution system should take into account the level of biosecurity required by the individual areas to which the water is distributed. (2) Hatchery design should include the physical separation or isolation of the different production facilities and effective perimeter security. (3) Installation of the embankments to stop the saltwater intrusion in the surrounding etc.
} 
livelihood system and remain food secure (Maxwell et al. 1999; Ahmed et al. 2010). Figure 12 explains how people of the current study area sequentially adopt different strategies in response to the increasing crisis.

Overall, it is impossible to stop brackishwater aquaculture in the study area, but sustainability can be attained if technically appropriate, economically viable, environmentally suitable, socially acceptable measures are taken. The present study projected some sustainable measures in an organized manner that the local people suggested in solving their different problems. Those are-

1) Instead of agricultural land, the fallow part of the region could be used for shrimp pond establishment. Maybe then the quantity and quality of agricultural land can be restored. Furthermore, rice production will continue besides aquaculture. However, to use the fallow parts, the irrigation department should take the initiative to establish a new canal network for those areas.

"...... as we are unable to oversee the permanent creation of a channel network on our own, only the government can do it. However, we have attempted to construct a channel in the fallow area to bring the cannel water in, but a substantial number of individuals are unwilling to give up their land to build the permanent channel."- Focus Group discussion, April 182021.

2) Excessive commercial production led to a small life span for the pond; farmers should balance the capacity and output.

3) Waterlogging from the brackish pond can be managed by proper drainage development.

According to one local panchayat official,

“... perhaps there is a conventional process for establishing shrimp farms, but it is not followed at the grassroots level due to a lack of clarity. When funds are available, we strive to build a good drainage system at fishery site so that saltwater intrusion on agricultural land may be handled from the panchayat side.”- Key Informant Interview (KII)- April 02, 2021.

4) Fish Rotation instead of monotonous shrimp can be the best option in restoring the productivity of brackishwater ponds. For the study area, they can crop 'tilapia' as an alternative.

First two years Shrimp $\rightarrow$ third Alternative fishes' $\rightarrow$ next two years Shrimp $\rightarrow$ six and seven Alternative fishes' $\rightarrow$ next two years Shrimp $\rightarrow 10$ and 11th Year Alternative fishes' $\rightarrow$ next year Shrimp; $\rightarrow$ 13th year Alternative fishes' $\rightarrow$ again one-year Shrimp

(Source: ISEC, Bangalore)

5) Government and local administration should strictly enforce standard operating procedures for shrimp farming. Like making embankments or keeping buffer area should be made compulsory for every pond. 
Lastly, at the point of time when a pandemic took the lives of people, this kind of household-level qualitative study was very much difficult. The accessibility to the field was limited because of the spreading of Covid 19. People are afraid to come together for focus group discussion as covid cases started increasing, although it was arranged by maintaining all the precautions and social distancing. Hence, further research is needed to capture the broader dimensions of livelihoods and environmental sustainability concerns in inland agriculture regions to make a generalized conclusion. Apart from this, there is a scope for an in-depth study regarding the role and ability of the local governments in managing the approaching livelihood and ecosystem vulnerabilities.

\section{Conclusion}

Increasing societal and biological demand in developing countries like India continuously pushes people towards the speedy and enormous accumulation of wealth with minimal concern about sustainability. The present paper depicts one of such incidents of hefty occupational transformation from relatively less profitable but sustainable agriculture to unsustainable capitalistic shrimp aquaculture. It also showed that combining high-resolution Google Earth images with a real-world field survey could be very useful in detecting changes in minute features. Small aquaculture farms now cover around 32 percent of the entire study area. The findings also highlight that the proficient use of available assets in the adopted alternative provides short-term and tremendous positive livelihood changes. Such as three times increase in income, developing human capital, and secure food. However, it is also noteworthy that these haphazard transformations have inconsistent production in the long run. The ongoing extreme commercialization will gradually convert this whole agriculturally prosperous region into a degraded wasteland. Therefore, the local government should be more aware of the potential hazards from this uncontrolled proliferation of aquaculture and strict enough to maintain the increasing problems. Otherwise, the entire ecosystem will demolish in the near future.

Acknowledgements We want to express our deepest gratitude and thanks to the reviewers and Prof. Yoshiro Higano, editor in chief of the journal 'Asia-Pacific Journal of Regional Science' for their valuable time and comments for upgrading the research work. We are also thankful to local panchayat officials for providing us with relevant pieces of information. Moreover, we express our gratitude to participants from the survey area; without their fruitful cooperation, it was pretty impossible to run this kind of field-based study in the COVID 19 pandemic situation. Credit also goes to Google for supplying the satellite images utilized in this investigation.

Funding No specific funding has been received to carry out this piece of research.

Data availability Land conversion and quantification related spatio-temporal remote sensing information were collected from Google Earth Pro-based high-resolution images. Other relevant materials were collected from the field with the help of a primary survey and focus group discussion. These survey databases may be available on relevant requests to the corresponding author. 


\section{Declarations}

Conflict of interest We would like to declare that we have no known competing financial interests or personal relationships that could have appeared to influence the work reported in this paper.

Informed consent Informed consent was obtained from all individual participants included in the study.

Consent for publication This paper has not yet been published and is not currently being considered for publication. This article has been authorized by both writers, and if accepted, it will not be published anywhere in the same manner, in English or any other language, even electronically, without the copyright holder's express agreement.

\section{References}

Adams H, Adger WN, Ahmad S et al (2020) Multidimensional well-being associated with economic dependence on ecosystem services in deltaic social-ecological systems of Bangladesh. Reg Environ Chang 20:1-16

Adnan S (2013) Land grabs and primitive accumulation in deltaic Bangladesh: interactions between neoliberal globalization, state interventions, power relations and peasant resistance. J Peasant Stud 40:87-128

Ahmed N, Troell M, Allison E, Muir JF (2010) Prawn postlarvae fishing in coastal Bangladesh: challenges for sustainable livelihoods. Mar Policy 34:218-227. https://doi.org/10.1016/j.marpol.2009. 06.008

Alemu GT, Nigussie Z, Haregeweyn N et al (2021) Cost-benefit analysis of on-farm grain storage hermetic bags among small-scale maize growers in northwestern Ethiopia. Crop Prot. https://doi.org/ 10.1016/j.cropro.2020.105478

Anzar M (2020) Depeasantization as a social process: a critical appraisal. Indian J Jurisprud Stud $1: 142-150$

Ashley C, Carney D (1999) Sustainable livelihoods: lessons from early experience. DFID, London

Mistri A (2019) Is the migration from indian sundarban an environmental migration? Investigating through sustainable livelihood approach (SLA). Asian Profile 47:195-219

Azad AK, Jensen KR, Lin CK (2009) Coastal aquaculture development in Bangladesh: unsustainable and sustainable experiences. Environ Manag 44:800-809. https://doi.org/10.1007/s00267-009-9356-y

Barnes C, Claus R, Driessen P et al (2017) Uniting Forest and livelihood outcomes? Analyzing external actor interventions in sustainable livelihoods in a community forest management context. Int J Commons 11:532-571. https://doi.org/10.18352/ijc.750

Belton B, Thilsted SH (2014) Fisheries in transition: food and nutrition security implications for the global South. Glob Food Sec 3:59-66. https://doi.org/10.1016/j.gfs.2013.10.001

Belton B, Reardon T, Zilberman D (2020) Sustainable commoditization of Seafood. Nat Sustain 3:677-684

CGWB (2018) GWYB 2018-2019. Government of India, pp. 1-17

Chakraborty S (2017) Study and verification of groundwater level at coastal areas of Purba Midnapur District in West Bengal by visual MODFLOW Software, Dissertation, Jadavpur University

Chougrani E, El Amrani MH (2021) The common heritage of humankind (CHH): visions of developed countries vs. developing countries. Social-ecological systems (SES). Springer, Berlin, pp 57-73. https://doi.org/10.1007/978-3-030-76247-6_3

Chowdhury MA, Khairun Y, Rahman M, Shivakoti PG (2010) Production economics as an indicator for sustainable development of shrimp farming. Asia Pac J Rural Dev 20:79-98. https://doi.org/10. $1177 / 1018529120100106$

Cui L, Shi J (2012) Urbanization and its environmental effects in Shanghai, China. Urban Clim 2:1-15. https://doi.org/10.1016/j.uclim.2012.10.008

Das Y, Mohanty UC, Jain I (2016) Development of tropical cyclone wind field for simulation of storm surge/sea surface height using numerical ocean model. Model Earth Syst Environ. https://oi.org/ 10.1007/s40808-015-0067-5 
Deng Z, Zhu X, He Q, Tang L (2019) Land use/land cover classification using time series Landsat 8 images in a heavily urbanized area. Adv Space Res 63:2144-2154

DFID (1999) Sustainable livelihoods guidance sheets introduction: overview. Sustainable Livelihoods Guidance Sheets, UK

Duarte CM, Marbá N, Holmer M (2007) Rapid domestication of marine species. Science 316:382-383. https://doi.org/10.1126/science.1138042

Dutta D, Sekhar C, Arnab D (2016) A geospatial study on spatio-temporal growth of brackish water aquaculture along the coastal areas of West Bengal (India). Model Earth Syst Environ 2:1-10. https://doi.org/10.1007/s40808-016-0109-7

El Bilali H, Hauser M, Berjan S, Miseckaite O, Probst L (2017) Rural livelihoods transitions: towards an integration of the sustainable livelihoods approach and the multi-level perspective. In: Raupeliene A (ed) Proceedings of the 8th international scientific conference rural development 2017. Lithuania, pp 1010-1016

Emadi M, Baghernejad M (2014) Comparison of spatial interpolation techniques for mapping soil $\mathrm{pH}$ and salinity in agricultural coastal areas, northern Iran. Arch Agron Soil Sci 60:1315-1327

Faysse N, Aguilhon L, Phiboon K, Purotaganon M (2020) Mainly farming... but what's next? The future of irrigated farms in Thailand. J Rural Stud 73:68-76

Food and Agriculture Organisation (2020) FAO Fish Stat. http://www.fao.org/fishery/statistics/software/ fishstatj/en. Accessed 26 Feb 2021

Freitas RR, Hartmann C, Tagliani PR, Poersch LH (2011) Evaluation of space adequateness of shrimp farms in Southern Brazil. Ann Acad Bras Ciênc 83:1069-1076

Frewer LJ, Howard C, Hedderley D, Shepherd R (1996) What determines trust in information about foodrelated risks? Underlying psychological constructs. Risk Anal 16:473-486

Gammage S, Swanburg K, Khandkar M, Islam MZ, Zobair M, Muzareba AM (2006) A gendered analysis of the shrimp sector in Bangladesh: greater access to trade and expansion. USAID, Dhaka

George R (2012) The Wiley-Blackwell encyclopaedia of globalization/ depeasantization, pp 282-294. https://doi.org/10.1002/9780470670590.wbeog140

Gurmu S, Biya M, Yadete E (2021) Comparative evaluation of transplanting and sowing on growth and Yield of Tef (Eragrostis tef (Zucc.)) at Jimma and Buno Bedele South Western Ethiopia. Eur J Biophys 9:61-71

Halder S, Dhal L, Jha MK (2021) Investigating groundwater condition and seawater intrusion status in coastal aquifer systems of eastern India. Water 13:1-15. https://doi.org/10.3390/w13141952

Hamid MA, Mohammad A (1998) Coming out of their homesteads?: employment for rural women in shrimp aquaculture in coastal Bangladesh. Int J Soc Econ 25:314-337. https://doi.org/10.1108/ 03068299810193489

Huang L, Yang L, Tuyến NT, Colmekcioglu N, Liu J (2021) Factors influencing the livelihood strategy choices of rural households in tourist destinations. J Sustain Tour. https://doi.org/10.1080/09669 582.2021 .1903015

Islam MS (2009) In search of "white gold": environmental and agrarian changes in rural Bangladesh. Soc Nat Resour 22:66-78. https://doi.org/10.1080/08941920801942255

Islam MR, Tabeta S (2019) Shrimp vs prawn-rice farming in Bangladesh: a comparative impacts study on local environments and livelihoods. Ocean Coast Manag 168:167-176

Jahan KM, Ahmed M, Belton B (2010) The impacts of aquaculture development on food security: lessons from Bangladesh. Aquac Res 41:481-495. https://doi.org/10.1111/j.1365-2109.2009.02337.x

Jahan KM, Belton B, Viswanathan KK (2014) Communication strategies for managing coastal fisheries conflicts in Bangladesh. Ocean Coast Manag 92:65-73. https://doi.org/10.1016/j.ocecoaman.2014. 01.003

Jayanthi M, Thirumurthy S, Samynathan M et al (2020) Assessment of land and water ecosystems capability to support aquaculture expansion in climate-vulnerable regions using analytical hierarchy process based geospatial analysis. J Environ Manag. https://doi.org/10.1016/j.jenvman.2020.110952

Johny TV, Madhusoodana KB (2007) Carbon/nitrogen ratio optimization and periphyton development on the production and sustainability of Penaeus monodon (fabricius) in extensive culture system. Doctoral dissertation, Cochin University of Science and Technology

Lawrence J, Peter C, Eckersley R (2013) Globalization and the environment by Peter Christoff and Robyn Eckersley. Glob Environ Polit 15:129-131. https://doi.org/10.1162/GLEP_r_00276

Le TN, Bregt AK, Van Halsema GE, Hellegers PJ, Nguyen LD (2018) Interplay between land-use dynamics and changes in hydrological regime in the Vietnamese Mekong Delta. Land Use Policy 73:269-280 
Lobb AE, Mazzocchi M, Traill WB (2007) Modelling risk perception and trust in food safety information within the theory of planned behaviour. Food Qual Prefer 18:384-395. https://doi.org/10.1016/j. foodqual.2006.04.004

Maiti A (2019) Socio-economic and production characteristics of Pacific White Shrimp, Litopenaeus Vannamei (Boone, 1931) Culture in Purba Medinipur, West Bengal, India. Int J Adv Res 7:10441052. https://doi.org/10.21474/ijar01/9311

Maity A, Saha B, Roy A (2019) Constraint analysis of Penaeus vannamei culture in Purba Medinipur district, West Bengal. J Inland Fish Soc India 51:163. https://doi.org/10.47780/jifsi.51.2.2019.106501

Maxwell D, Ahiadeke C, Levin C, Armar-Klemesu M et al (1999) Alternative food-security indicators: revisiting the frequency and severity of coping strategies. Food Policy 24:411-429

Merino G, Barange M, Blanchard LJ et al (2012) Can marine fisheries and aquaculture meet fish demand from a growing human population in a changing climate? Glob Environ Chang 22:795-806. https:// doi.org/10.1016/j.gloenvcha.2012.03.003

Migotto M, Davis B, Carletto C, Beegle K (2008) Measuring food security using respondents' perception of food consumption adequacy. Food security: indicators, measurement, and the impact of trade openness. Oxford University Press, Oxford. https://doi.org/10.1093/acprof:oso/9780199236558.003. 0002

Musa M, Lusiana ED, Buwono NR, Arsad S, Mahmudi M (2020) The effectiveness of silvofishery system in water treatment in intensive whiteleg shrimp (Litopenaeus vannamei) ponds, Probolinggo District, East Java, Indonesia. Biodivers J Biol Divers. https://doi.org/10.13057/biodiv/d211031

Na M, Gross AL, West KP (2015) Validation of the food access survey tool to assess household food insecurity in rural Bangladesh Biostatistics and methods. BMC Public Health. https://doi.org/10. 1186/s12889-015-2208-1

NABARD (2018) Sectoral paper on fisheries and aquaculture 86. https://www.nabard.org/auth/writereadd ata/file/Fisheries\%20and\%20Aquaculture.pdf

Naylor RL, Goldburg RJ, Primavera JH et al (2000) Effect of aquaculture on world fish supplies. Nature 405:1017-1024

Nguyen Tan D (2021) How do livelihood assets affect the environmental sustainability of shrimp farming? A case study in Tra Vinh province, Vietnam. Egy J Aquat Biol Fish 25:15-41

Ojha A, Chakrabarty A (2018) Brackish water aquaculture development and its impacts on agriculture land: a case study on coastal blocks of Purba Medinipur district, West Bengal, India using multitemporal Satellite data and GIS Techniques. Int J Appl Eng Res 13:10115-10123

Pahl-Wostl C, Basurto X, Villamayor-Tomas S (2021) Comparative case study analysis. The Routledge handbook of research methods for social-ecological systems. Routledge, England, pp 282-294

Paprocki K, Cons J (2014) Life in a shrimp zone: aqua- and other cultures of Bangladesh's coastal landscape. J Peasant Stud 41:1109-1130. https://doi.org/10.1080/03066150.2014.937709

Pattanaik S (2000) Conservation of environment and protection of marginalized fishing communities of lake Chilika in Orissa, India. J Hum Ecol 22:291-302

Prasad KA, Ottinger M, Wei C, Leinenkugel P (2019) Assessment of coastal aquaculture for India from sentinel-1 SAR time series. Remote Sens 11:357. https://doi.org/10.3390/rs11030357

Primavera JH (1997) Socioeconomic impacts of shrimp culture. Aquac Res 28:815-827

Rajakumari S, Sundari S, Meenambikai M, Divya V (2020) Impact analysis of land use dynamics on coastal features of Deshapran block, Purba East Medinipur, West Bengal. J Coast Conserv. https:// doi.org/10.1007/s11852-020-00737-9

Rajarshi M, Santra SC (2011) Influence of Brackish water aquaculture on soil salinisation. Int J Res Chem Environ 1:60-65

Rwanga SS, Ndambuki JM (2017) Accuracy assessment of land use/land cover classification using remote sensing and GIS. Int J Geosci 8:611-622

Schmidt M, Soentgen J, Zapf H (2020) Environmental humanities: an emerging field of transdisciplinary research. GAIA Ecol Perspect Sci Soc 29:225-229

Sharmin S, Ali RN (2005) Socioeconomic analysis on factors contributing to household income of the stakeholders involved in shrimp industry of Bangladesh. Bangladesh J Agric Econ 2:85-96

Show S (2018) Cost of cultivation and profitability of agriculture in West Bengal: a study with special reference to Backward Region of West Bengal. Econ Aff 63:1067-1075

Talukdar S, Singha P, Mahato S, Pal S, Liou YA, Rahman A (2020) Land-use land-cover classification by machine learning classifiers for satellite observations-a review. Remote Sens. https://doi.org/10. $3390 / \mathrm{rs} 12071135$ 
The Fish Site (2021) Shrimp farming proves a mixed blessing in West Bengal. https://thefishsite.com/ articles/shrimp-farming-proves-a-mixed-blessing-in-west-bengal. Accessed 21 Oct 212021

Toufique KA, Belton B (2014) Is aquaculture pro-poor? Empirical evidence of impacts on fish consumption in Bangladesh. World Dev 64:609-620. https://doi.org/10.1016/j.worlddev.2014.06.035

USAID (2006) A pro-poor analysis of the shrimp sector a pro-poor analysis of the shrimp sector, U.S. Agency for International Development

Wang W, Lan Y, Wang X (2021) Impact of livelihood capital endowment on poverty alleviation of households under rural land consolidation. Land Use Policy. https://doi.org/10.1016/j.landusepol.2021. 105608

Williams JJ, Esteves LS, Rochford LA (2015) Modelling storm responses on a high-energy coastline with XBeach. Model Earth Syst Environ. https://doi.org/10.1007/s40808-015-0003-8

Publisher's Note Springer Nature remains neutral with regard to jurisdictional claims in published maps and institutional affiliations. 